\title{
Myalgias and muscle contractures as the presenting signs of Addison's disease
}

\author{
M.S. Shapiro, C. Trebich, L. Shilo and L. Shenkman \\ Department of Medicine C and the Endocrine Unit, Meir Hospital, Sapir Medical Center, Kfar Sava, \\ and the Sackler School of Medicine, Tel Aviv, University, Tel Aviv, Israel.
}

\begin{abstract}
Summary: Severe generalized myalgias and muscle contractures of the lower extremities were the major initial manifestations of adrenal insufficiency in a 26 year old black male. The intensity of increased skin pigmentation was not fully appreciated until the patient's skin colour was compared to that of his brother. Replacement with physiological doses of gluco- and mineralocorticoids was associated with complete amelioration of symptomatology.
\end{abstract}

\section{Introduction}

Addison's disease masquerading as a prominent musculoskeletal abnormality is an uncommon manifestation of this disorder. We present an unusual case of Addison's disease in a black subject in whom rheumatological symptoms obscured the otherwise obvious diagnosis of adrenal insufficiency.

\section{Case report}

A 26 year old black male was hospitalized because of generalized muscle weakness, myalgias, difficulties in extension of the lower extremities, and arthralgias. He was unable to walk.

The patient had immigrated to Israel two years previously from Ethiopia. He was well until three months prior to his admission when he began to note general weakness and muscular pains which were most marked in the lower extremities. In particular, there was difficulty in straightening the lower extremities. He was referred to the emergency ward for investigation after a negative evaluation for a rheumatic disorder.

At this time he stressed the presence of pains in the lower extremities and in difficulties in straightening the lower limbs. He also added that his skin colour, especially on the palms and soles, had become darker.

On examination the patient was in distress. The blood pressure was $110 / 70 \mathrm{mmHg}$, the pulse $80 / \mathrm{min}$.

Correspondence: M.S. Shapiro, M.D., Endocrine Unit, Meir Hospital, $44281 \mathrm{Kfar}$ Sava, Israel.

Accepted: 23 September 1987
Hyperpigmentation was especially noted on his tongue, in the buccal cavity and on the palms and soles of his feet. The degree of pigmentation noted was impressive when compared to the colour of his brother. Muscle contractures of the lower extremities were prominent and pain was elicited on attempting to straighten the limbs. The remainder of the examination was normal.

Laboratory evaluation showed a haemoglobin of $15.0 \mathrm{~g} / \mathrm{dl}$ and a white blood count of $6.0 \times 10^{9} / 1$. The serum glucose was $3.74 \mathrm{mmol} / \mathrm{l}$, the sodium $137 \mathrm{mmol} / 1$, the potassium $5.5 \mathrm{mmol} / 1$, the urea nitrogen $2.57 \mathrm{mmol}$ urea/l, the creatinine $106 \mu \mathrm{mol} / \mathrm{l}$, the calcium $2.2 \mathrm{mmol} / \mathrm{l}$, phosphorus $0.96 \mathrm{mmol} / \mathrm{l}$, bicarbonate $29 \mathrm{mmol} / \mathrm{l}$, creatine kinase (CK) $80 \mathrm{U} / 1$, lactate dehydrogenase (LDH) $60 \mathrm{U} / 1$, aspartate aminotransferase (SGOT) $20 \mathrm{U} / 1$, total thyroxine $\left(\mathrm{T}_{4}\right) 70 \mathrm{nmol} / \mathrm{l}$.

The plasma cortisol was $27.6 \mathrm{nmol} / \mathrm{l}$ (normal 138 $635 \mathrm{nmol} / \mathrm{l}$ ) and failed to rise after administration of tetracosactrin (Synacthen) depot $1 \mathrm{mg}$ twice daily for 4 days. The basal plasma ACTH was $600 \mathrm{ng} / 1$ (normal $20-80 \mathrm{ng} / \mathrm{l}$ ). The plasma aldosterone was $1.12 \mathrm{nmol} / \mathrm{l}$ and the plasma renin activity $10 \mu \mathrm{g} / \mathrm{h} / \mathrm{l}$ (mean control values \pm s.d. $5.81 \pm 3.30$ and $6.11 \pm 0.09$, respectively) after assuming the erect position for 4 hours. There was also no aldosterone response to administration of Synacthen depot. Following administration of cortisone acetate $37.5 \mathrm{mg}$ and fludrocortisone acetate $0.1 \mathrm{mg}$ for 3 days his symptoms resolved completely.

An electromyogram was not performed until the fourth day of administration of hormone replacement. No myopathic changes were noted. Inasmuch

(C) The Fellowship of Postgraduate Medicine, 1988 
as the serum CK, SGOT, LDH and electromyogram were normal, a muscle biopsy was not obtained.

The chest X-ray did not disclose the presence of tuberculosis but the Mantoux test was highly positive. The patient previously resided in an endemic area of tuberculosis and therefore received rifampicin and ethambutol. There was no need to increase the dose of the cortisol replacement during the period of treatment with rifampicin.

\section{Discussion}

Diffuse myalgias, muscle contractures and arthralgias predominated the clinical picture in this patient. His symptoms simulated a rheumatic disorder and the diagnosis of adrenal insufficiency was not, at first, considered. His complaint of darkening of the skin initially was not heeded because of his ethnic origin. The relief of all muscle and joint symptomatology following administration of physiological hormone replacement was dramatic documentation of the presence of Addison's disease.

Diffuse myalgias and arthralgias have been described among the presenting symptoms of adrenal insufficiency in $6-13 \%$ of affected individuals. ${ }^{1,2}$ The diagnosis may be readily considered in the presence of other characteristic symptoms and findings. When, however, the 'rheumatic' component is the predominant feature of adrenal insufficiency, the diagnosis may be obfuscated. Migratory arthralgias of 12 months' duration were the presenting symptom of Addison's

\section{References}

1. Thorn, W.G., Dorrance, S.S. \& Day, E. Addison's disease: evaluation of synthetic desoxycorticosterone acetate therapy in 158 patients. Ann Int Med 1942, 16: 1053-1096.

2. Nerup, J. Addison's disease - clinical studies: a report of 108 cases. Acta Endocrinol 1974, 76: 27-41.

3. Calabrese, H. \& White, C.S. Musculoskeletal manifestations of Addison's disease. Arthritis Rheum 1979, 22: 558 .

4. Yunus, A., Masi, A.T. \& Allen, J.P. Hypothalamic hypopituitarism presenting with rheumatologic symptoms. Arthritis Rheum 1981, 24: 632-635.

5. VanderLaan, W.L., Flexion deformities in adrenal insufficiency. J Clin Invest 1955, 34: 968-969.

6. Slater, J.D. Stiffman syndrome with atypical hypopituitarism. J Soc Med 1960, 53: 867-869.

7. Weisenbaugh, P.E. \& Heller, H.M. Flexion contractures in Addison's disease. $J$ Clin Endocrinol Metab 1960, 20: 792-794.

8. Adams, R.D., Denny-Brown D. \& Pearson, C.M. In: Disease of Muscle: A Study in Pathology, chapter 11. Harper and Row, New York, 1962, p 609. disease in a 40 year old female. ${ }^{3}$ A 37 year old male with hypothalamic hypopituitarism also presented with diffuse musculoskeletal pain. Symptoms resolved in both patients within 4 days of administration of physiological doses of glucocorticoids. ${ }^{4}$ Flexion contractures have preceded the diagnosis of adrenal insufficiency, with time intervals ranging from 3 months to 5 years. ${ }^{5-10}$ Our case, like most previously described patients, responded dramatically to administration of glucocorticoid therapy. Patients with flexion contractures may, however, require orthopaedic corrective measures to overcome the deformities. ${ }^{10}$

The lack of electrolyte changes in this patient is not a total surprise. Normal serum sodium concentrations were found in $61 \%$ and serum potassium in $72 \%$ of patients with Addisonian crisis. ${ }^{11}$ The lack of serum enzyme changes indicates lack of active muscle necrosis in the pathophysiology of this manifestation. Biopsies of muscle from contracted areas have been normal. ${ }^{8}$ Interestingly, administration of a single dose of $40 \mathrm{mg}$ of prednisolone to normal subjects has been followed by myalgias, stiffness and arthralgias. ${ }^{12}$ The term 'steroid pseudo-rheumatism' has been applied to these symptoms occurring either during or after prolonged steroid therapy. ${ }^{13}$ Alterations in intracellular sodium and potassium have been implicated in the development of tendon contractures. ${ }^{14}$ The basic pathophysiological mechanism of the rheumatic syndromes associated with alterations in plasma glucocorticoid levels remains unclear.

Consideration of adrenal insufficiency in the presence of these symptoms may lead to a rapid diagnosis and successful therapy.

9. Stewart, A.G. \& Sprunt, J.G. Hypopituitarism and flexor muscle spasm. Acta Endocrinol 1966, 53: 489498.

10. Susac, J.O., Henry, J.M. \& Deller, J.J. Flexion contracture in adrenal insufficiency. Arch Phys Med Rehabil 1968, 49: 13-16.

11. Knowlton, A.I. Addison's disease: A review of its clinical course and management. In: Christy, N.C. (ed) The Human Adrenal Cortex. Harper and Row, New York, 1971, p 329.

12. Good, T.A., Benton, J.W. \& Kelley, V.C. Symptomatology resulting from withdrawal of steroid hormone therapy. Arth Rheum 1959, 2: 299-301.

13. Robinson, B.H.B., Mattingly, D. \& Cope, C.L Adrenal function after prolonged corticosteroid therapy, $\mathrm{Br}$ Med J 1962, 1: 1579-1584.

14. Thorn, G.W. In: The Diagnosis and Treatment of Adrenal Insufficiency. Charles C. Thomas, Springfield, Illinois, 1949. 